\title{
Integrated database for rapid mass movements in Norway
}

\author{
C. Jaedicke ${ }^{1}$, K. Lied ${ }^{1}$, and K. Kronholm ${ }^{1,2}$ \\ ${ }^{1}$ Norwegian Geotechnical Institute NGI, Oslo, Norway \\ ${ }^{2}$ International Centre for Geohazards ICG, Oslo, Norway
}

Received: 1 July 2008 - Revised: 29 January 2009 - Accepted: 9 March 2009 - Published: 31 March 2009

\begin{abstract}
Rapid gravitational slope mass movements include all kinds of short term relocation of geological material, snow or ice. Traditionally, information about such events is collected separately in different databases covering selected geographical regions and types of movement. In Norway the terrain is susceptible to all types of rapid gravitational slope mass movements ranging from single rocks hitting roads and houses to large snow avalanches and rock slides where entire mountainsides collapse into fjords creating flood waves and endangering large areas. In addition, quick clay slides occur in desalinated marine sediments in South Eastern and Mid Norway. For the authorities and inhabitants of endangered areas, the type of threat is of minor importance and mitigation measures have to consider several types of rapid mass movements simultaneously.
\end{abstract}

An integrated national database for all types of rapid mass movements built around individual events has been established. Only three data entries are mandatory: time, location and type of movement. The remaining optional parameters enable recording of detailed information about the terrain, materials involved and damages caused. Pictures, movies and other documentation can be uploaded into the database. A web-based graphical user interface has been developed allowing new events to be entered, as well as editing and querying for all events. An integration of the database into a GIS system is currently under development.

Datasets from various national sources like the road authorities and the Geological Survey of Norway were imported into the database. Today, the database contains 33000 rapid mass movement events from the last five hundred years covering the entire country. A first analysis of the data shows that the most frequent type of recorded rapid mass movement is rock slides and snow avalanches followed by debris slides in third place. Most events are recorded in the steep fjord

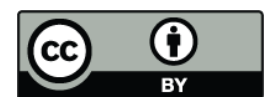

Correspondence to: C. Jaedicke (cj@ngi.no) terrain of the Norwegian west coast, but major events are recorded all over the country. Snow avalanches account for most fatalities, while large rock slides causing flood waves and huge quick clay slides are the most damaging individual events in terms of damage to infrastructure and property and for causing multiple fatalities. The quality of the data is strongly influenced by the personal engagement of local observers and varying observation routines. This database is a unique source for statistical analysis including, risk analysis and the relation between rapid mass movements and climate. The database of rapid mass movement events will also facilitate validation of national hazard and risk maps.

\section{Introduction}

Norway has a land area of $323802 \mathrm{~km}^{2}$ of which only $2.7 \%$ is arable land. Approximately $30 \%$ of the total land area is covered by mountains. Slopes over 30 degrees steepness cover $6.7 \%$ of the country (Fig. 1a). The country is dominated by the Scandinavian Mountain chain, reaching from the southern tip of the country all the way to the Russian border and dividing the country into western and eastern parts. The climate is a mild maritime climate with high amounts of precipitation on the west side of the mountain chain (Fig. 1b). The tree line decreases from ca. $800 \mathrm{~m}$ in the south to sea level in the north.

Large areas in Norway are exposed to all kinds of rapid mass movements. Snow avalanches threaten roads, railroads and settlements during winter time, while slushflows are active during early winter and spring. Rock slides and debris slides can occur during the whole year but mainly in periods with heavy rains. Huge rock slides of several million cubic meters are a threat to many of the Norwegian fjords, where damage caused by flood waves can destroy tens of kilometres of shore line and single events have killed a large number of Norwegians (Anda and Blikra, 1998). Our definition

Published by Copernicus Publications on behalf of the European Geosciences Union. 


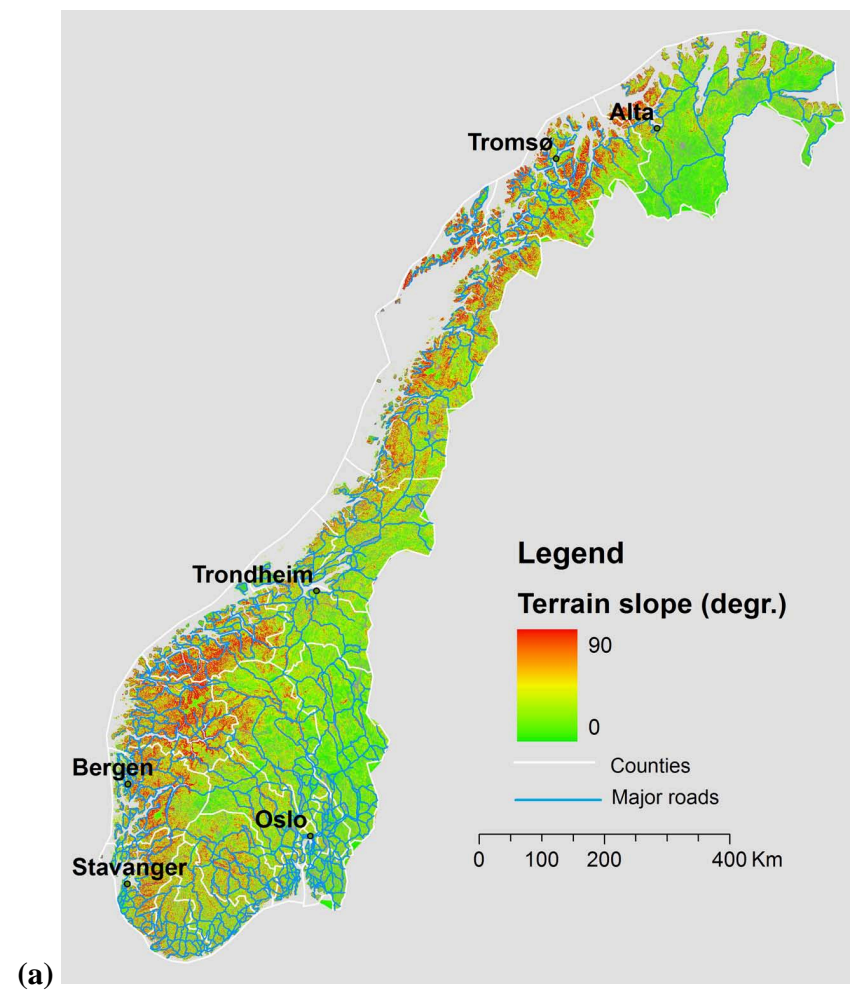

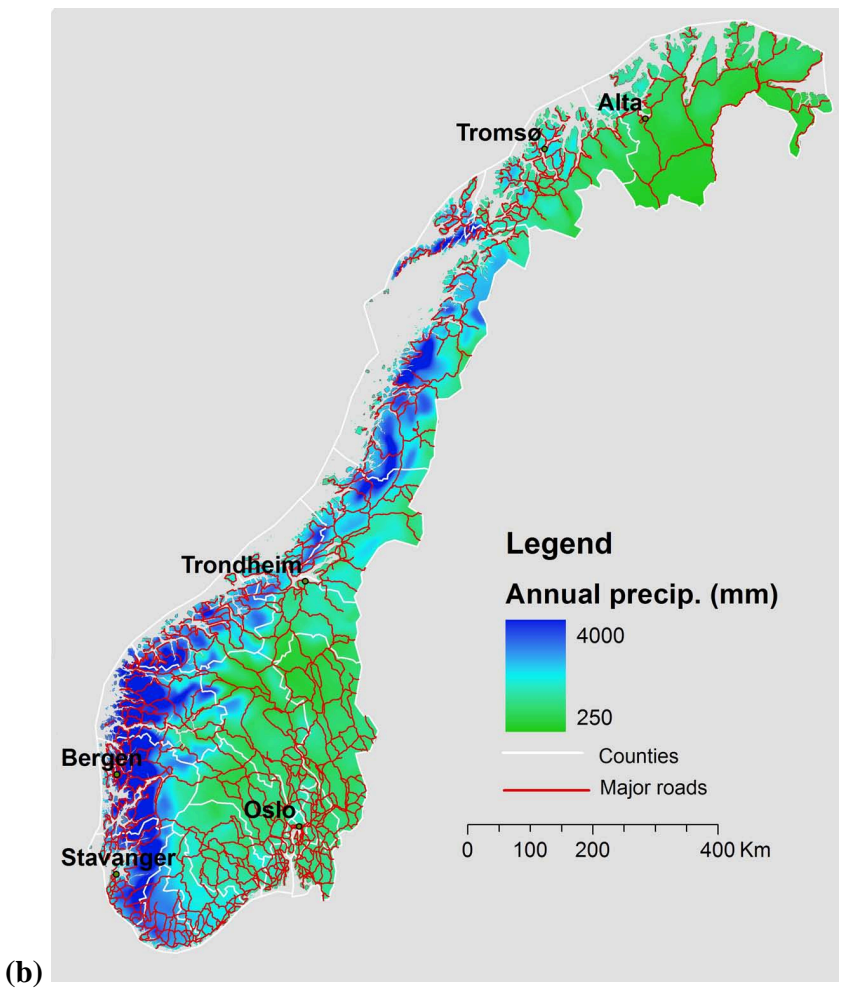

Fig. 1. (a) Map of Norway showing terrain slope in degrees. (b) Map of Norway showing the annual precipitation in mm (Datasource: www.met.no).

of rapid mass movements includes all types of rapid gravitational mass movement in natural materials. In this paper the general term slide is used for rapid mass movements.

National databases of landslides (movements in geological materials) have been developed in many countries, e.g. Italy (Guzetti et al, 1994), New Zealand (Glade and Crozier, 1996), Nicaragua (Devoli et al, 2007). Most of these inventories exclude snow avalanches, ice falls and subaqueous slides which are usually considered in separate collections (Garcia and Jamard, 2002; Harvey, 2002a). National authorities in Switzerland established an integrated database for slides and floods (StorMe, 2002). To our knowledge this is the only database to combine all types of slides in a single integrated database.

During the last 150 years, approximately 2000 people have been killed by all kinds of slides in Norway. Most of the fatalities occurred in homes and at work sites. On average, the number of fatalities due to debris slides has decreased in recent years while leisure time fatalities in snow avalanches have increased and now account for the majority of snow avalanche fatalities. Historical events were documented when serious damage to property and persons occurred. Documentation of slide events improved significantly in the 17 th century when events were written down in church registers and other public documents. Furseth (2006) presents a historical overview of the most severe events in
Norway. The communities of the western Norwegian fjord lands have suffered great losses in single events. Three major rock slides created flood waves in fjords or lakes (Tafjord 1934, Loen 1905 and 1936) that killed 175 people in total.

Quick clay slides are a special feature of the Norwegian geology. The earliest documented events are clay slides mentioned in the Dipl. Norvegicum and the Icelandic sagas (1100 in Stjørdal and 1345 in Støren with 500 casualties). In 1978 the Rissa skredet in Trøndelag moved 5-6 million $\mathrm{m}^{3}$ from an area of $3.3 \mathrm{~km}^{2}$ leaving a $1.5-\mathrm{km}$ long scarp. One person was killed and 14 farms were completely destroyed. The worst year of snow avalanche fatalities was 1868 when 161 people were killed (Kristensen, 1991; Lied and Kristensen, 2003). Recently mudflows and snow avalanches hitting roads have caused infrastructure damage and killed road users (Fig. 2).

Systematic collection of slide events is crucial to establish a solid base for statistical and spatial analysis of these events on a variety of scales from local to national. There are two different approaches for registering slides:

a) The first and historically used method is the identification of an active mass movement slope. Each path is identified and consecutive mass movements are associated with this path. This approach is based on the experience that snow avalanches and mudflows appear up to several times annually in the same path. The approach is less applicable to rock slides, debris slides and quick 
(a)

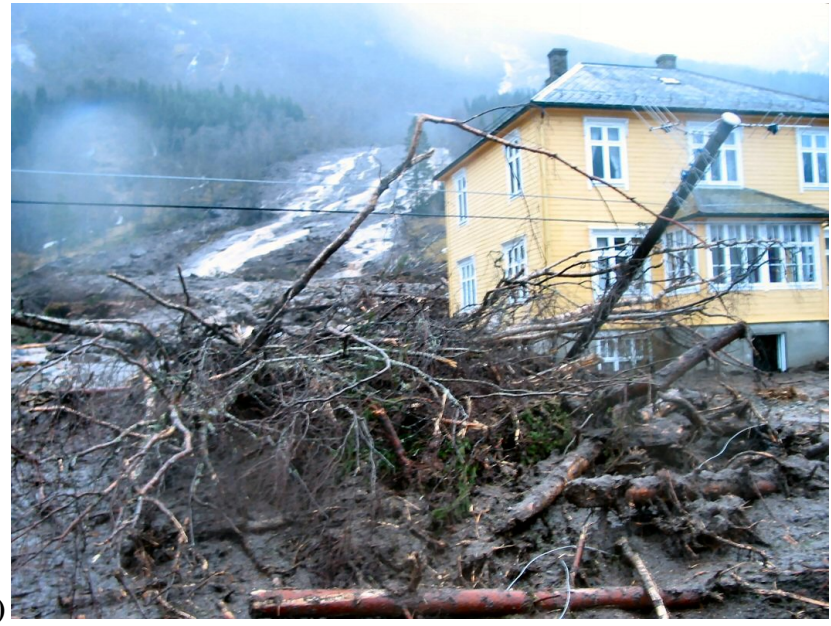

(b)

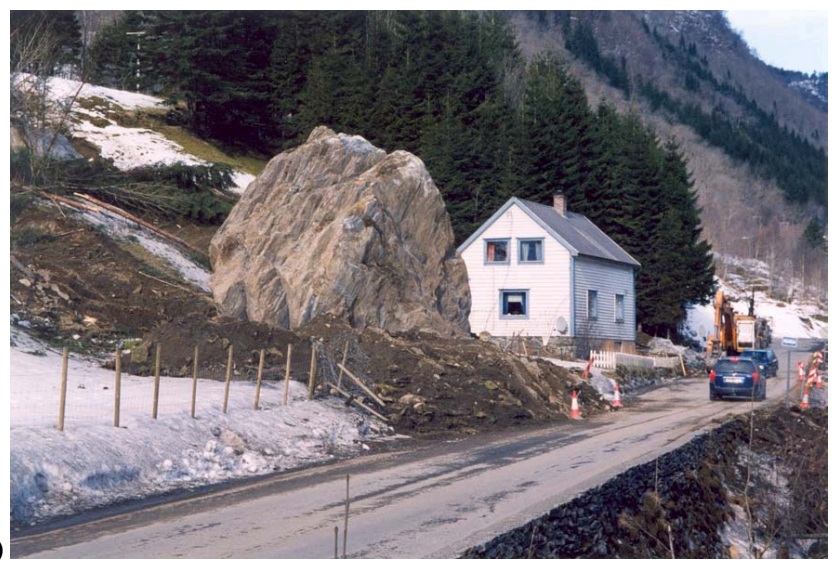

Fig. 2. (a) Landslide in Berstad 14 November 2005. (b) Rock slide in Mundheim, 9 March 2003.

clay slides, where only one event may occur at a certain location within a timescale of several decades.

b) The other approach is registering each slide event as an independent occurrence that is identified by type, date and location (as point or polygon features). This is a more versatile method that allows the registration of all types of slides in the same database.

Approach b) is chosen for the current database since it covers the need of all types of slide events as well as the type of data of the existing datasets.

Records of mass movement events have been collected by different persons and institutions in Norway during the last 30 years. The objectives of these collections vary greatly from source to source. Usually, only one type of slide is included and only a short period of time or limited area is covered. Norwegian examples of such inventories are the NGI snow avalanche collection of 200 extreme run out avalanches (Lied and Bakkehøi, 1980), the 3600 historically documented events involving damage and fatalities collected at the Geological Survey of Norway (NGU) (Furseth, 2003) and records of slides held by the Directorate of Public Roads and the National Rail Administration.

The database described in this paper is a database for all types of slides and was first established within the GeoExtreme project (Jaedicke et al., 2008). This is a four year project to study the climate change effects on slide activity in Norway. The objective of this database is to provide a national collection that gives an overview of historical mass movement events in Norway and can serve as the basis for statistical analyses and consulting work. All digitally tabulated events available in Norway should be imported into the database. It also includes concise definitions for all the involved parameters, based on national and international standards.

\section{Materials and methods}

\subsection{Data}

The first known systematic records of slide events are available from the 1930s when snow avalanche paths and events were recorded in different inventories in Norway (Ramsli, 1953). Usually one district or valley was mapped at a time and the data documented in maps and reports. The aim of these maps and reports was to document where debris slides and snow avalanches had occurred so new development in areas prone to these hazards could be avoided. This work continued with varying intensity until the early 1970s when the snow avalanche group at NGI was established.

Systematic reporting of slide events affecting roads was started in 1973 by the Norwegian Directorate of Public Roads (Lied, 1993). This database is today the biggest single collection of Norwegian slide events and includes more than 24500 slide events of all types. The data is collected by local road maintenance teams as they encounter slide deposits on or near roads. The events are all dated, classified by slide type and given location relative to the road system.

Since 1998 the Geological Survey of Norway (NGU) has started collecting historical slide events that caused significant damage. Furseth (2003) uses various sources such as interviews of locals, church registers and other archive materials to gather information on mass movement events in Norway. More than 3600 slide events have been collected often with detailed information on date, location and damage. The Norwegian National Rail Administration also maintains an inventory with 2100 slide events.

The slide events are all registered as single point features. The location of the point in the area affected by the slide varies from source to source. While road and rail registrations usually pick the spot where the slide hits the 
Table 1. Overview of the data sources used in the database.

\begin{tabular}{llll}
\hline Source & Type of movement & No. of events & Time range \\
\hline $\begin{array}{l}\text { Road } \\
\text { authorities }\end{array}$ & All types & ca. 24500 & $1973-2008$ \\
$\begin{array}{l}\text { Rail } \\
\text { authorities }\end{array}$ & All types & ca. 2100 & $1937-2008$ \\
NGI & Snow avalanches & ca. 2370 & $1973-2004$ \\
& Sub aqueous slides & ca. 30 & $8000 \mathrm{BP}<-2004$ \\
& Quick clay slides & ca. 510 & $915-2002$ \\
NGU & Debris slides & ca. 90 & 2000 \\
Total & All types & ca. 3600 & $900-2008$ \\
\hline & All types & ca. 33000 & \\
\hline
\end{tabular}

road or railway, some of the NGI registered slides pick the release area of avalanches. The NGU data often picks the location of the damaged object or killed people. The database offers the ability to register polygons for the slide extent and several points for each damaged object or person. These features are used for future recordings into the database.

Digitization of older maps and reports will be continued in the upcoming years. An overview of the included datasets is given in Table 1.

It is a stated aim to bring all available slide data into this present database and efforts are being made to encourage donations of private collections to the database. However, this presents some difficulties, since most collections have their own system for storing and defining the data.

\subsection{Structure}

The database is constructed for individual events of slides. Only three parameters are mandatory: location, time, type of movement. All other information is optional. The location is stored as a point in projected geographical positions (UTM, WGS84). Outlines of slides are only available for special cases. The dating of the event requires at least a nominated year for the event. Often no exact date during the year is known. This is taken into account by setting the data accuracy field to "not known when during year". Other predefined accuracy definitions can be chosen both for dating (from $\pm 5 \mathrm{~min}$ to \pm 50 years) and location (from $\pm 1 \mathrm{~m}$ to $\pm 50 \mathrm{~km})$.

Substantial time has been used to define slide types and subtypes (Table 2) in accordance with nationally and internationally used classifications (Cruden and Varnes, 1996; Highland, 2004; UNESCO, 1981). It is our intention to give database users the ability to choose from a range of a) slide materials, b) water contents and c) slide movement types. We have deliberately avoided defining each possible slide event in detail because these definitions might change with time. The definitions of slide material, water content and slide movement type are more fundamental and less likely to be subject to misinterpretation.
The optional parameters are grouped in different classes (Fig. 3). General parameters include information that is available for any type of event e.g. slope angle, geometry (fall height, run out, width), name of municipality and county. More specific parameters depend on which type of movement is reported. This class includes parameters such as geological setting, snow type, grain size, soil type, water content etc. Secondary parameters give information about damages, rescue operations, victims and other effects of the slide event (Fig. 3). All text fields are connected to predefined lists, giving a range of possible values. Number fields are always followed by an accuracy field to be able to register the quality of the collected data. Wherever possible, parameters follow international standards (UNESCO, 1981; Harvey, 2002b; ISO 14689-1, 2003; American Society for Testing and Materials, 1985, etc.). In total, 385 parameters are included in the database.

The data quality can vary considerably depending on the source of the data, the person doing the recording and local conditions at the time of reporting. Therefore, each event can have one of four quality levels (Table 3). New entries will be continuously evaluated by the database administrator who will check the validity accuracy of the report and assigns the appropriate quality level. The database is implemented in Oracle and the user interface is web-based.

\subsection{Graphical user interface}

The graphical user interface for the database is programmed in .NET and available online as an interactive webpage.

All users have to register and can access the database via a user name and password. This allows the administrator to identify the person who reports a slide. Further, creation and editing of events is logged. Users can have the status of layman, expert or administrator, where layman is the default. Expert and administrator status is only given to persons with documented qualifications.

Different pages can be accessed after the login. The reporting of new events is the heart of the application. Here all parameters for a new event can be entered. The form is built in a modular hierarchy. On the first page, the mandatory parameters (time, location, type) are entered together with a list of ten yes/no questions regarding the involvement of persons, damages etc., all of which are No by default (Fig. 4).

The remaining reporting is modular and based on the selections made on the first page. The user is guided through a series of pages, starting with the general terrain parameters and type specific parameters. The following pages only appear if the user has ticked off for Yes on the first page. For example a page for the registration of damage on buildings only appears if "building affected" is ticked off on the first page. The last page provides the ability to enter a free text in addition to all other information. This is left to the last page to motivate the user to categorize their information instead of writing a report. 


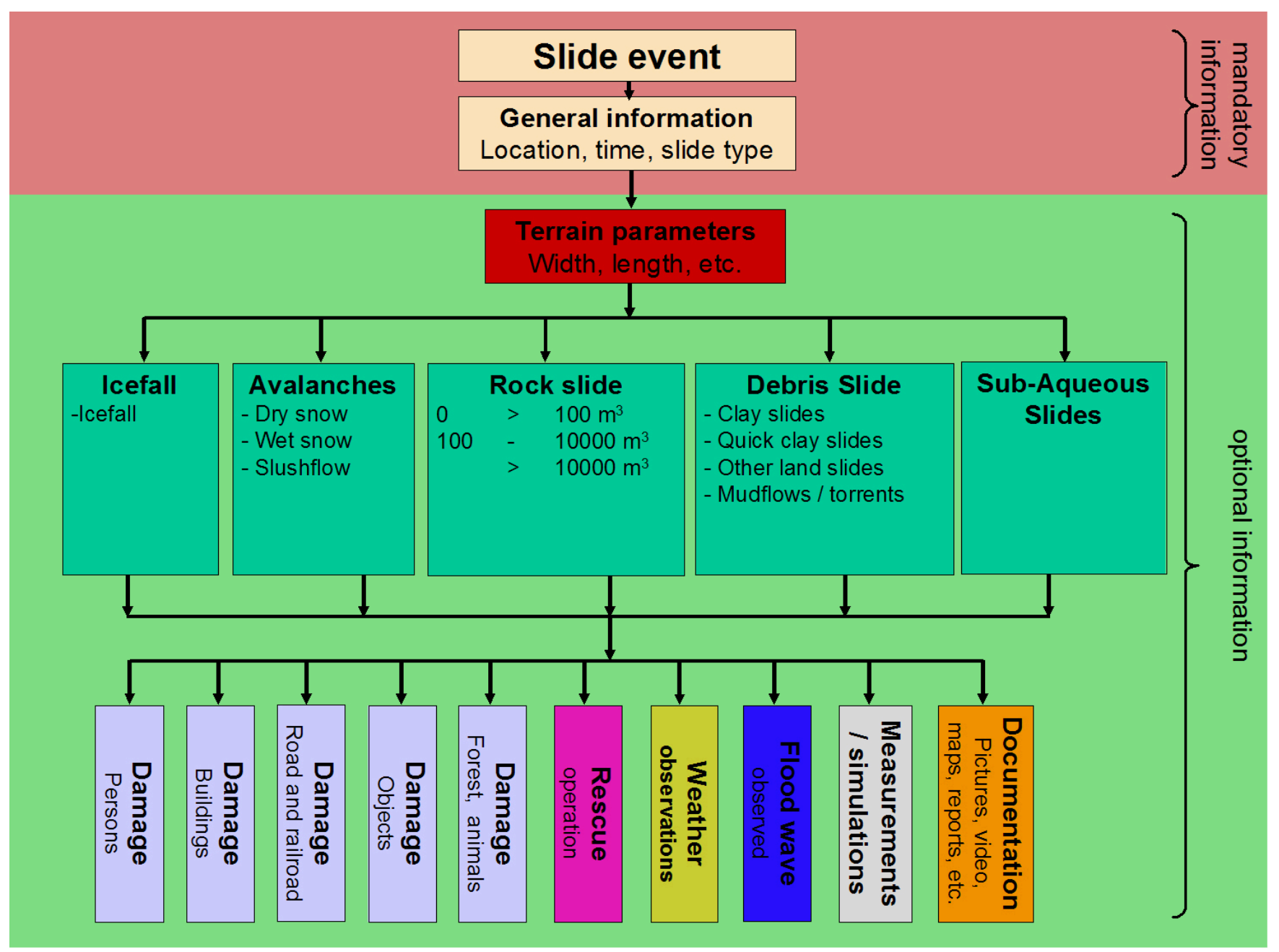

Fig. 3. Structure of the slide database. The only mandatory data is the location, time and slide type. All other information is optional.

Fast and effective recording of new events is an important aim. The first page with the mandatory parameters should be able to be filled in within one minute. To assist this, drop down menus with pre-defined values are used wherever applicable. All number values are followed by an accuracy estimate that is also pre-defined in drop down menus. If available, files like pictures, movies, documents and modeling results can be uploaded to the database (Fig. 3).

Different standard queries (my slides, slides of last $24 \mathrm{~h}$, all slides) allow the user a fast and easy access to existing data. Each user can edit events they have entered and view all other events. Additionally, the administrator can use these queries to change the events quality level and delete events.

An important reason for establishing the database is the need to search the collected data. The search page (Fig. 5) allows searching for all 385 parameters in the database. All parameters can be combined creating custom search strings. The results can be listed online or be exported to ascii or EXCEL files. A graphical presentation of the location of the data on a map is currently under development showing different queries to the data, e.g. slide type, slides causing fatalities etc. (www.skrednett.no, in Norwegian).

\subsection{Meteorological data}

Meteorological data is imported into the database for use in statistical analysis. For all events where the date of the event was better known than +/- one day, a set of two direct (daily temperature and $24 \mathrm{~h}$ precipitation) and 20 derived (accumulated precipitation, snow, dry, wet periods etc.) weather parameters were calculated at the Norwegian Meteorological Institute and automatically assigned to the slide event. The data sources are interpolated fields on a $1-\mathrm{km}$ grid covering the whole country. The interpolations are based on the daily synoptical observations at weather stations throughout Norway (Tveito et al., 2000, 2005). This dataset is available for the period from 1960 until today and covers most of the slide records in the database. The meteorological data has been 
Table 2. The available types and sub types of slides used in the database.

\begin{tabular}{|c|c|c|c|c|}
\hline Type & Subtype & Short definition & Norwegian type & Norwegian sub type \\
\hline Avalanche & $\begin{array}{l}\text { Dry snow } \\
\text { Wet snow } \\
\text { Slushflow }\end{array}$ & all types of snow & Snøskred & $\begin{array}{l}\text { Tørr snø } \\
\text { Våt snø } \\
\text { Sørpe }\end{array}$ \\
\hline Rock slide & $\begin{array}{l}0-100 \mathrm{~m}^{2} \\
100-10000 \mathrm{~m}^{2} \\
>10000 \mathrm{~m}^{2}\end{array}$ & solid rock material of different volumes & Steinskred & $\begin{array}{l}\text { Steinsprang } \\
\text { Lite fjellskred } \\
\text { Fjellskred }\end{array}$ \\
\hline Debris slide & $\begin{array}{l}\text { Clay slides } \\
\text { Quick clay slides } \\
\text { Other debris slides } \\
\text { Mudflows/torrents }\end{array}$ & $\begin{array}{l}\text { clay materials } \\
\text { chemically destabilized } \\
\text { marine clay materials } \\
\text { loose geological material } \\
\text { loose geological material } \\
\text { with dominating water fraction }\end{array}$ & Løsmasseskred & $\begin{array}{l}\text { Leire } \\
\text { Kvikkleire } \\
\text { Løsmasse } \\
\text { Flomskred }\end{array}$ \\
\hline Icefall & No sub type & all types of ice & Isnedfall & \\
\hline Sub-aqueous slide & No sub type & $\begin{array}{l}\text { all types of movements } \\
\text { under the water surface }\end{array}$ & Undervannskred & \\
\hline
\end{tabular}

Table 3. Definition of the four quality levels of the events.

\begin{tabular}{|c|c|c|}
\hline Level & Definition & Action \\
\hline 0 & $\begin{array}{l}\text { Registration not completed } \\
\text { (Time or location or event type not registered) }\end{array}$ & $\begin{array}{l}\text { Event is not accepted } \\
\text { Event will not be shown in lists and searches }\end{array}$ \\
\hline 1 & Registration completed, not verified & Event is accepted, editable by the user \\
\hline 2 & Registration completed, verified, information missing & $\begin{array}{l}\text { Event is checked by the administrator } \\
\text { More information can be added } \\
\text { Event is locked for editing by the user }\end{array}$ \\
\hline 3 & Registration completed, verified, information complete & $\begin{array}{l}\text { Event is checked by the administrator } \\
\text { All available information is included } \\
\text { Event is locked for editing by the user }\end{array}$ \\
\hline
\end{tabular}

and can be used to study the relationships between various meteorological parameters and the different types of slide. A detailed presentation of the applied statistical methods used in these studies is given in Kronholm et al. (2006).

\section{Results}

Currently, 33000 slides are included in the database. Figure 6 shows a map with events sorted by type of mass movement. The majority of the events were recorded by the road authorities. This can easily be seen as most of the events are close to the main roads in Norway. The spatial distribution of reported events is biased towards the valleys with population and infrastructure. In the coastal districts snow avalanches and rock slides dominate. The inland districts are more prone to debris slides and rock slide events. Debris slides rarely oc- cur in the northern half of the country. In total numbers, most events are rock slides, followed by snow avalanches (Fig. 7).

Most fatalities and damages from slide events in Norway are caused by snow avalanches, followed by rock slides (Fig. 7). Figure 8 shows most events only cause one fatality. Catastrophic events with 20 or more fatalities are rare (approximately once in 50 years).

An annual distribution of the different types of slides (Fig. 9) shows that the highest snow avalanche activity is expected between December and April. Debris slides activity is almost equally distributed throughout the year with minor peaks in July and November. The rock slide activity is highest in the winter months from January to April.

The spatial distribution of slide events throughout Norway shows a bias with most events occurring on the west coast and fewer events in Eastern Norway. It also shows that in some areas events are under-reported because the topogra- 


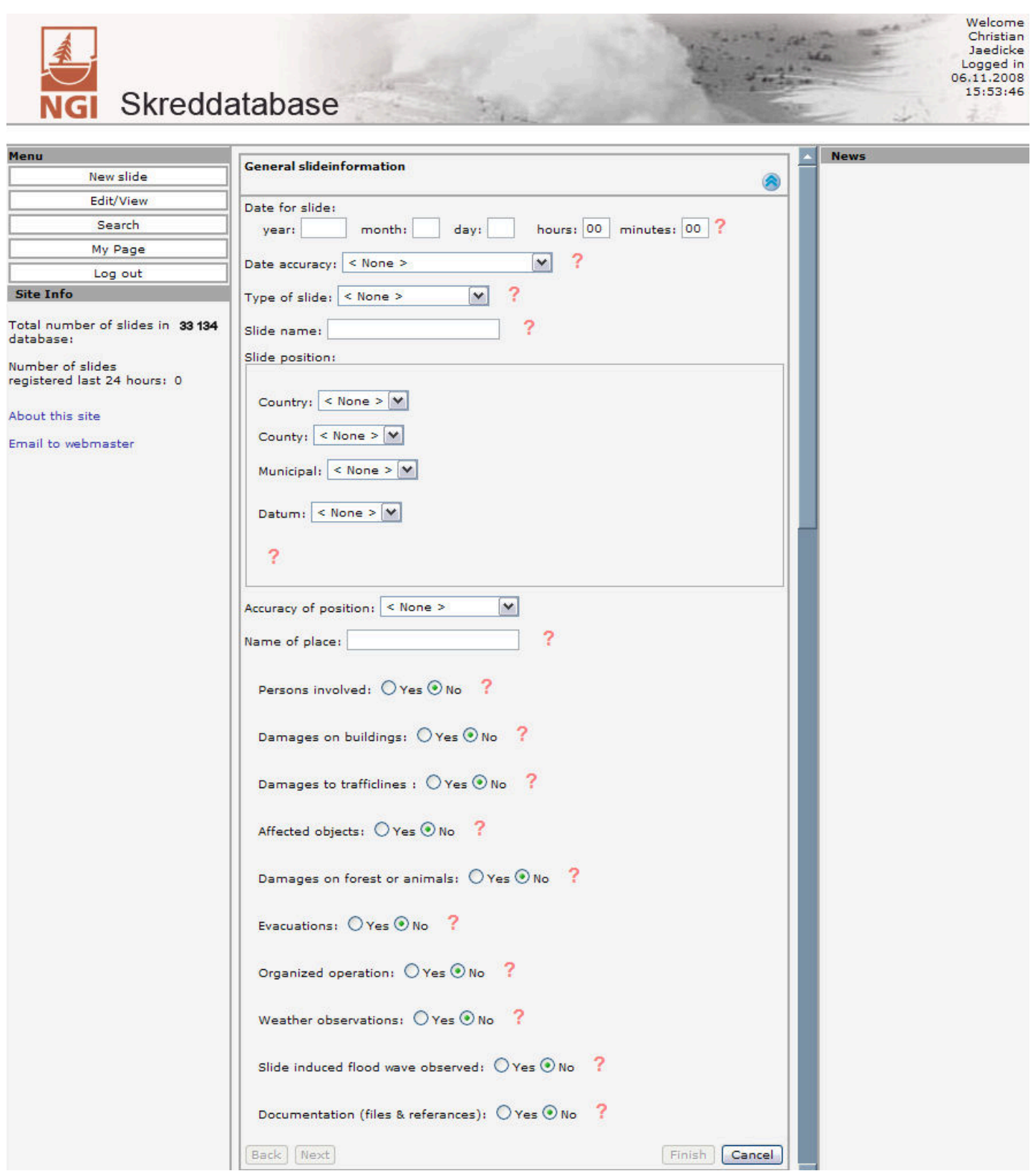

Fig. 4. Screen plot of the registration page.

phy indicates that there is a high likelihood of mass movements occurring in these areas but there are few records in the database.

The recorded slide events are neither well distributed in time nor in space so a frequency analysis of events is ruled out with this dataset. However, combining slide events with a uniform set of weather data is a way to bypass this limitation. The statistical analysis of the weather data shows a clear pattern (Kronholm et al., 2006). Snow avalanches and mudflows show the closest relationship to short term weather parameters. These events are often predicted by parameters such as $24 \mathrm{~h}$ precipitation, temperature and wind action. Rock and debris slides have a much lower correlation with weather parameters in general and short term parameters especially. Long term precipitation seems to be an important issue for debris slides and also for small volume rock slide activity. But also the geographical location of different regions plays an important role. This effect is especially notable for snow avalanches. Avalanches in West Norway are mostly released by direct action from precipitation, but wind plays the most important role in the coastal areas of Finmark in the northern most part of the country. 


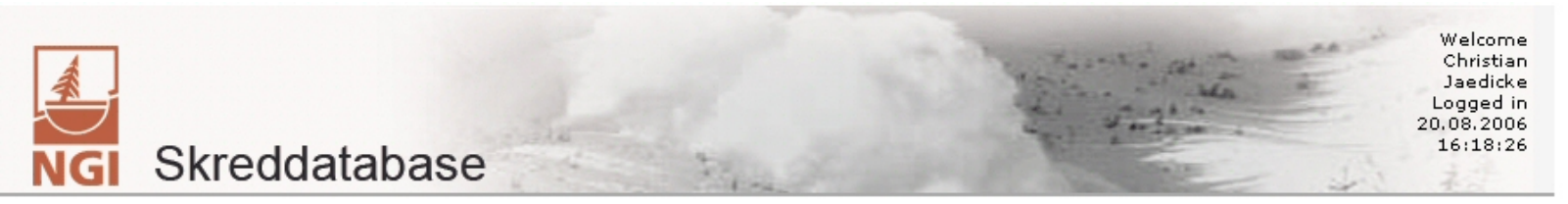

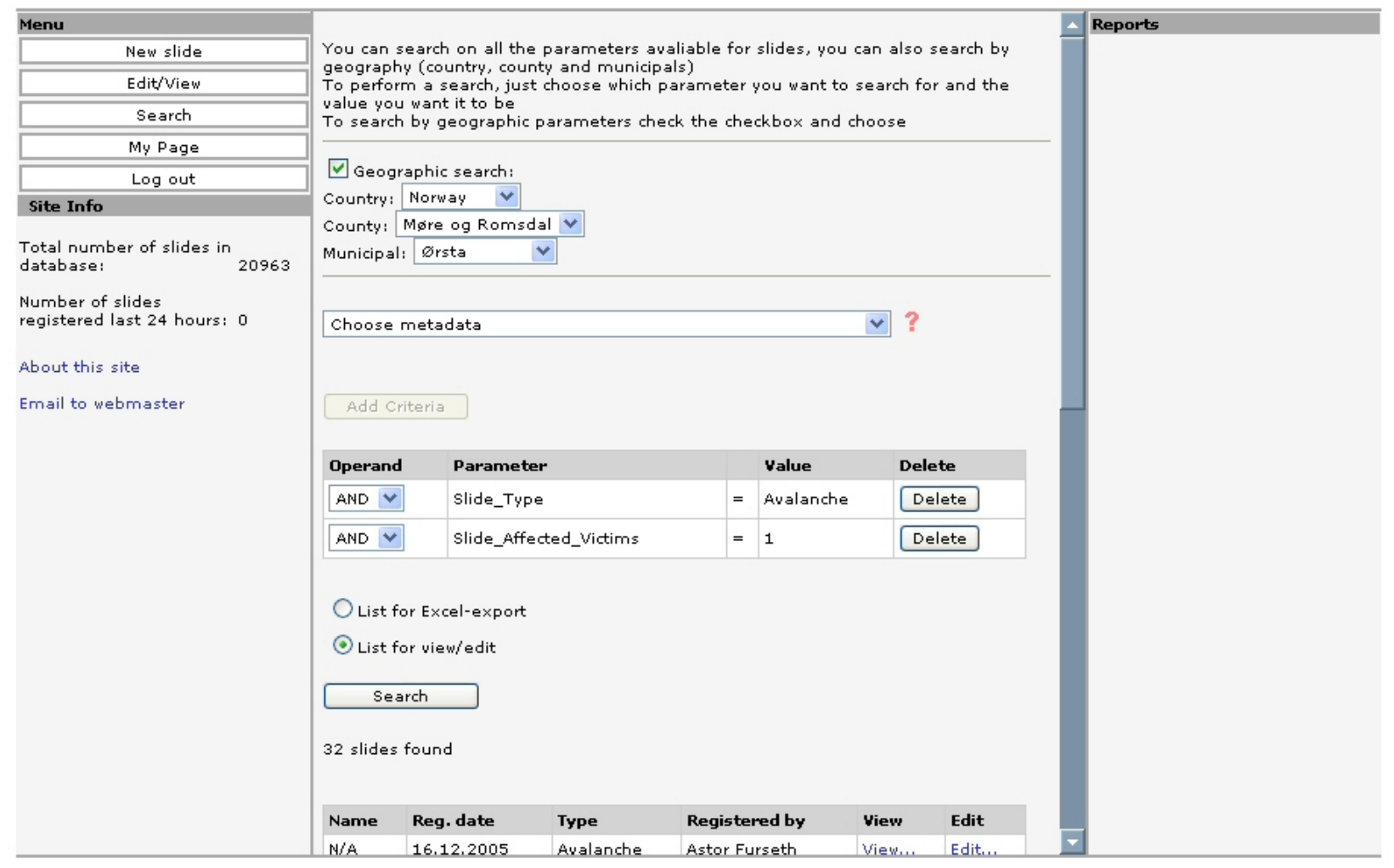

Fig. 5. Screen plot of the search page.

\section{Discussion}

The attempt to establish a nationwide database of slides has met some limitations. Traditionally, each scientific and administrative organization establishes a database designed to serve their specific field of interest and use. Also the thinking around geo-referenced data has changed significantly during recent years. This makes the construction of a homogeneous dataset for historical slide events a difficult task.

The following points about the new database presented in this paper should be noted: Firstly, the data are irregularly distributed in both time and space.

a) The number of observations has strongly increased since the 1970's, when the first systematic observations were started. However, data is still missing for considerable periods.

b) The amount of data collected as well as the data quality depends on the personal enthusiasm of the observers. As a result some districts show very limited or no records, even if the terrain suggests a high activity of slides.

c) Events prior to the $1960 \mathrm{~s}$ are mostly limited to events that caused fatalities and/or considerable damage. This limitation makes analyzing event frequencies difficult. Such an analysis requires a comparable data collection routine for a period of at least some decades.

d) The earliest snow avalanche and debris slide mapping studies focused only on the detection of active slide paths, not on identification of exact dates for individual events.

e) Data has been primarily collected in and close to infrastructure and settlements. Events in uninhabited terrain are seldom reported, again limiting the possibility for frequency and spatial distribution analysis.

Secondly, the collected parameters vary between sources used to compile the database. Each slide dataset or collection has a different focus and this has resulted in a large variation 


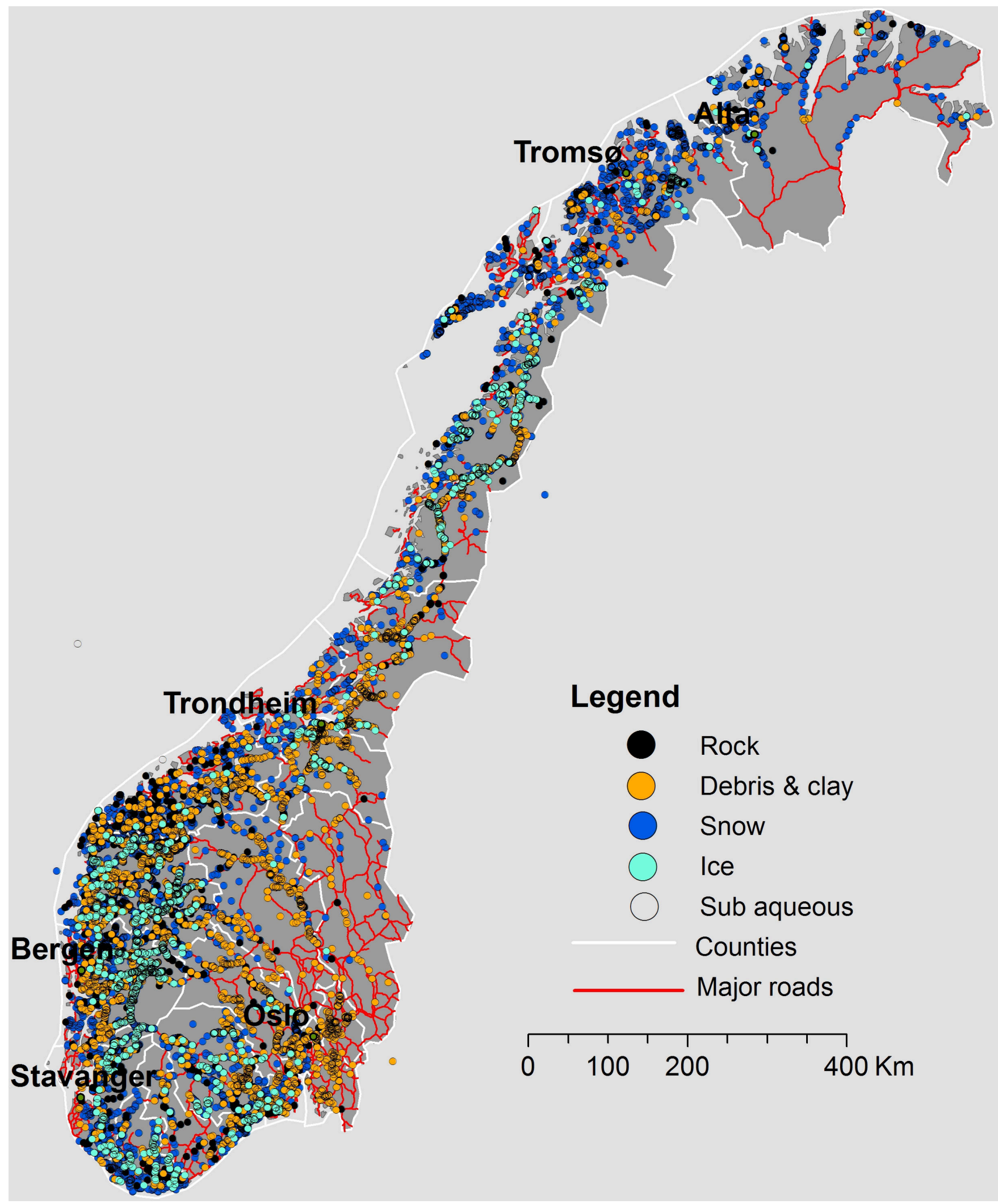

Fig. 6. Map of Norway showing slide events classified by slide type. 


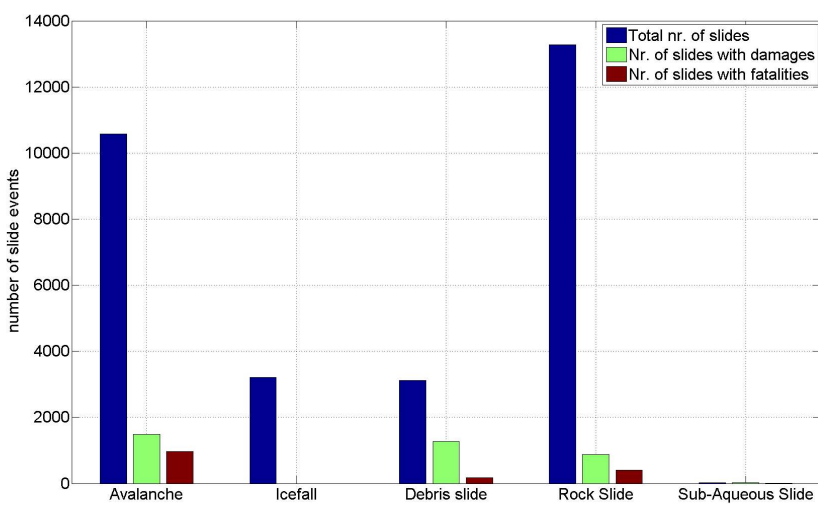

Fig. 7. Overview over slide types in the database and their contribution to damages and fatalities.

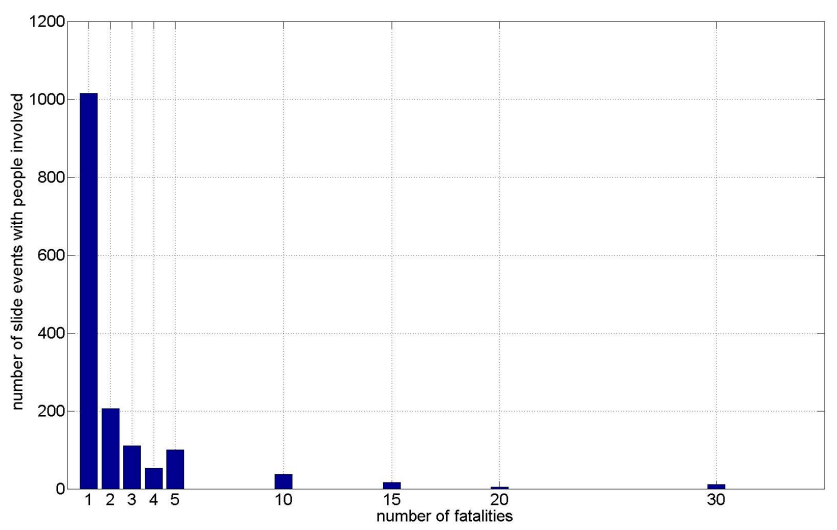

Fig. 8. Number of fatalities in a single event.

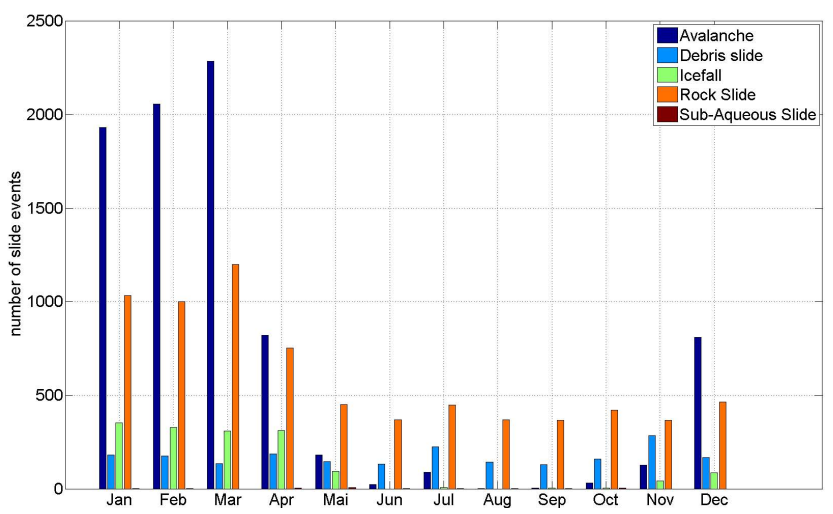

Fig. 9. Annual distribution of slide type. in the parameters that have been recorded. The required minimum information for a dataset to be included in the current database is time, location and type of movement. However, often additional parameters are available and including these in the database allows wider analysis of the data in the future. All the parameters from the source datasets were incorporated in the database for this reason.

For statistical analysis it is important to know whether the lack of slide reports on a certain day really means that there were no events in nature. The answer to this question is clearly, "no". The number of real and unreported slide events most likely exceeds the recorded events by several orders of magnitude. However, the records for large events with several fatalities and considerable damage included in the database are likely to be nearly complete (especially post 1945).

Despite these limitations, the database is of high value for a wide range of analyses. The spatial distribution of slides reveals the types of mass movement that dominate in the different parts of the country. Also, the distribution of the slides through the seasons shows the influence of seasonal weather patterns on the occurrence of different slide types. The minor peak of debris slides in July, for example, coincides with the convective precipitation and thunderstorms often prevalent during this warm summer month. The secondary peak in November is a result of the long lasting rain events in the autumn while evapotranspiration reached its minimum. Equally, the high rock slide activity in winter can be explained by the increased number of frost cycles during this season.

The most valuable application is the use of the data in statistical and GIS analysis where climate and topographical data is included. This type of analysis allows for establishing relationships between weather and mass movement events, type and topographical or geological conditions and also consequence analysis for infrastructure. The analysis by Kronholm et al. (2006) shows clearly that the different types of slides have different climatic triggers and that these triggers also depend on the geographical location in the country. These results will be used in a national hazard and risk analysis of the whole country for slide events.

\section{Conclusions}

The national database of slides for Norway offers a unique national collection that incorporates all currently available records in Norway. The data quality is generally high, but limitations exist mainly in the spatial and temporal distribution of the data. The database gives a good overview of slide events in Norway, providing information on the most exposed areas, the regional distribution of types and annual distributions. A graphical user interface was developed to allow a wide range of users to register, report and view mass movement events. Statistical analyses based on the database 
are possible and show interesting results. However, the number of reported slide events is a subset of a much larger number of real events that are never reported.

To improve the data quality in the future, data have to be collected more systematically. Standardized field questionnaires that can be used during field campaigns for later registration on the database web side could improve the data quality significantly. The database will be developed further with both new events and historical events that are digitized from the archives of the national organizations.

Acknowledgements. The development of the NGI slide database was financed by the Research Council of Norway through a Snow avalanche grant and the GeoExtreme project (RCN Grant no. $164885 / \mathrm{S} 30$ ), NGU and NGI. The data was kindly provided by NGU (Astor Furseth), the Directorate of Public Roads, the National Railroad Administration, the International Centre for Geohazards (ICG) and the NGI snow avalanche group.

Edited by: T. Glade

Reviewed by: G. Dellow and A. Guenther

\section{References}

American Society for Testing and Materials: D 2487-83, Classification of Soils for Engineering Purposes: Annual Book of ASTM Standards, 04.08, 395-408, 1985.

Anda, E. and Blikra, L. H: Rock-avalanche hazard in Møre \& Romsdal western Norway, in: 25 years of snow avalanche research, edited by: Hestnes, E., Voss 12-16 May 1998, Proceedings, Oslo, Norwegian Geotechnical Insitute, 1998.

Cruden, D. M. and Varnes, D. J.: Landslide types and processes, in: Landslides investigation and mitigation, special report 247 , edited by: Turner, A. K. and Schuster, R. L., Transportation Research Board, National Research Council, Washington, 36-75, 1996.

Devoli, G., Strauch, W., Guillermo, C., and Høeg, K.: A landslide database for Nicaragua: a tool for landslide-hazard management, Landslides, 4, 163-176, 2007,

Furseth, A.: Slide accidents in Norway, GEO magasinet, 8, 17-20, 2003 (in Norwegian).

Furseth, A.: Slide accidents in Norway, Tun Forlag, Oslo, 2006 (in Norwegian).

Garcia, S. and Jamard, A. L.: L'enquête permanente sur les Avalanches. Statistique générale descriptive des événements et des sites des donées de l'EPA, Rapoort technique Cemagref, 100 pp., 2002.

Glade, T. and Crozier, M. J.: Towards a national landslide information base for New Zealand, NZ Geogr, 52(1), 29-40, 1996.

Guzetti, F., Cardinali, M., and Reichenbach, P.: The AVI projects: a bibliographical and archive inventory of landslides and floods in Italy, Environ Manage, 18(4), 623-633, 1994.

Harvey, S : Avalanche incidents in Switzerland in relation to the predicted danger degree, proceedings of the ISSW 2002, Penticton, British Columbia, 6 pp., 2002a.

Harvey, S.: Eingabedokumentation zur neuen Schadenlawinendatenbank (Lawinen- und Personentabelle), Swiss Institute for Snow and Avalanche Research, Davos Switzerland, 2002b.
Highland, L: Landslide types and processes, USGS fact sheet 20043072, available at: ttp://pubs.usgs.gov/fs/2002/3072/, 2004.

ISO 14689-1: Geotechnical investigation and testing - Identification and classification of rock, International Organization for Standardization, 2003.

Jaedicke, C., Solheim, A., Blikra, L. H., Stalsberg, K., Sorteberg, A., Aaheim, A., Kronholm, K., Vikhamar-Schuler, D., Isaksen, K., Sletten, K., Kristensen, K., Barstad, I., Melchiorre, C., Høydal, Ø. A., and Mestl, H.: Spatial and temporal variations of Norwegian geohazards in a changing climate, the GeoExtreme Project, Nat. Hazards Earth Syst. Sci., 8, 893-904, 2008, http://www.nat-hazards-earth-syst-sci.net/8/893/2008/.

Kristensen, K.: Snow Avalanche Accidents in Norway, Symposium de Chamonix CISA-IKAR/ANENA, 92-100, 1991.

Kronholm, K., Vikhamar-Schuler, D., Jaedicke, C., Isaksen, K., Sorteberg, A., and Kristensen, K.: Forecasting snow avalanche activity from meteorological data using classification trees and logistic models; Grasdalen, western Norway, proceedings of the ISSW 2006, Telluride, Colorado, 2006.

Lied, K.: Snow avalanche experience through 20 years, Lauritz Bjerrum Memorial Fund, Norwegian Geotechnical Institute, 42 pp., 1993.

Lied, K. and Bakkehøi, S.: Empirical calculations of snow avalanche runout distance based on topographic parameters, J. Glaciol., 26(94), 165-177, 1980.

Lied, K. and Kristensen, K.: Snow Avalanches, handbook about snow avalanches, Vet tog Viten forlag, Oslo, 200 pp., 2003 (in Norwegian).

Ramsli, G.: Snow avalanches in the district of Møre and Romsdal, Norwegian Geotechnical Institute report, 12 pp., 1953 (in Norwegian).

StorMe: Benutzerhandbuch (users manual), Eidgenösische Forstdirektion, Bern, Switzerland, 29 pp., 2002.

Tveito, O. E., Bjørdal, I., Skjelvåg, A. O., and Aune, B.: A GIS based agro-exologicaldecision system based on gridded climatology, Meteorol. Appl., 12(1), 57-68, 2005.

Tveito, O. E., Førland, E., Heino, R., Hanssen-Bauer, I., Alexandersson, H., Dalström, B., Drebs, A., Kern-Hansen, C., Jónsson, T., Vaarby Laursen, E., and Westman, Y.: Nordic temperature maps, DNMI Report, 09/00, 54 pp., 2000.

UNESCO: Avalanche Atlas. International Commission on Snow and Ice of the international association of hydrological sciences, International Association of Hydrologic Sciences, 256 pp., 1981. 